\title{
Analysis of the application results of the traditional vacuum preloading method: A case study
}

\author{
Wenbin $\mathrm{Liu}^{1,2,3,4^{*}}$ \\ ${ }^{1}$ Tianjin Port Engineering Institute Co., Ltd. Of CCCC First harbor engineering Co., Ltd., Tianjin, 300222, China \\ ${ }^{2}$ CCCC First Harbor Engineering Company Ltd., Tianjin, China \\ ${ }^{3}$ Key Laboratory of Port Geotechnical Engineering, Ministry of Communications, PRC, Tianjin, China \\ ${ }^{4}$ Key Laboratory of Port Geotechnical Engineering of Tianjin, Tianjin, China
}

\begin{abstract}
The traditional vacuum preloading method is a common way for enhancing the bearing strength of the soft clay layer. In general, a serious of plastic drainage boards are plugged into the soft clay foundation, and a sand layer is covered above the soft clay layer to establish a space for lateral drainage of the clay before applicating vacuum load. This paper analysed the application results of the traditional vacuum preloading method with the help of the data from an engineering case. The in-site testing data of the variation of the pore pressure in clay layer and the settlement are collected to evaluate the benefit of traditional vacuum preloading method.
\end{abstract}

\section{Introduction}

The developing society need more land area, and the shorts of land area in the coastal cities is especially acute. The reclamation project is a reliable and convenient solution for this problem. In consideration of the engineering cost and the influence on the environment, the reclamation projects usually take use of the mud from channel dredging, which is regarded as environmentharmed waste, in forming the land. Therefore, the threaten on environment and the shortage of land forming properties are both solved together.

In 1952, Kjellman raised [1-5] the concept of applicating vacuum to preload soft clay foundation [1-5], and the application of this method occured in some cases in America and Japan. But limiting by the immature sealing technology and vertical drainage equipment and skill at that time, the application of vacuum preloading method, the performance was not as well as expected. In 1984, Tianjin Port Engineering Institute Co., Ltd carried out a serious of successful pilot scale test of the combination of the vacuum preloading and the surcharge preloading. The equivalent preloading load in these tests reached up to 70 to $92 \mathrm{kPa}$. And the high value of the vacuum meets the usage needs for most of the storage yard, road, and industrial construction s.

This paper studied the application effect of the traditional vacuum preloading method. The in-site test method to assess the improvement of the foundation strength was based on the testing data of the surface settlement, changing in pore pressure and settlements of different layers.

\section{The information of the practical project}

The case used in this paper locates at Lianyungang area. The traditional vacuum preloading method is choosed for treating the soft clay. The backfilled area is formed by soft mud with very high water content (up to $120 \%$ or $130 \%$ ), small-permeability (less than $7-10 \mathrm{~cm} / \mathrm{s}$ ) and weak vertical bearing capacity (nearly equals to $0 \mathrm{kPa}$ ) mud. The backfilled mud cannot be a foundation until it is enforced to reach a high strength. In the practice, we choose the traditional vacuum preloading method to achieve this goal.

The area of the whole testing yard reaches $39451 \mathrm{~m}^{2}$. The top layer of the test yard is the $0.5 \mathrm{~m}$ deep, and is formed by the medium coarse sand. The $18 \mathrm{~m}$ deep standard plastic drainage board was plugged into the foundation with the interval of $1 \mathrm{~m}$ in lateral direction with square-shape layout. The exporting value of vacuum load is $85 \mathrm{kPa}$, and the actual loading duration of the vacuum load lasts for 150 days. The specific value of the properties of different soil layers below the sand layer in this experiment yard are concluded in Table 1. 
Table 1 Parameters of soil layers

\begin{tabular}{cccccc}
\hline Layer & $\begin{array}{c}\text { Thickness } \\
(\mathrm{m})\end{array}$ & $\begin{array}{c}\text { Weight } \\
\left(\mathrm{kN} / \mathrm{m}^{3}\right)\end{array}$ & $\begin{array}{c}\text { Sub-weight } \\
\left(\mathrm{kN} / \mathrm{m}^{3}\right)\end{array}$ & $\begin{array}{c}\text { Shearing strength } \\
\text { Cohesion } \\
\text { force } \\
(\mathrm{kPa})\end{array}$ & $\begin{array}{c}\text { Angle of the internal } \\
\text { friction } \\
\left({ }^{\circ}\right)\end{array}$ \\
\hline Dredger filled mud & 6.1 & 15.9 & 5.9 & 14.1 & 7.92 \\
Mud & 2.2 & 16.2 & 6.2 & 14.57 & 7.67 \\
Silty clay & 2.7 & 18.5 & 8.5 & 18.93 & 12.13 \\
Silty & 7.8 & 19.3 & 9.3 & 5.23 & 28.97 \\
Clay & 6.2 & 18.8 & 8.8 & 20.71 & 10.42 \\
\hline
\end{tabular}

\section{Testing data}

The changing of settlement on the surface of the experiment yard during the loading duration is shown in Fig.1.

\subsection{Settlement of the surface}

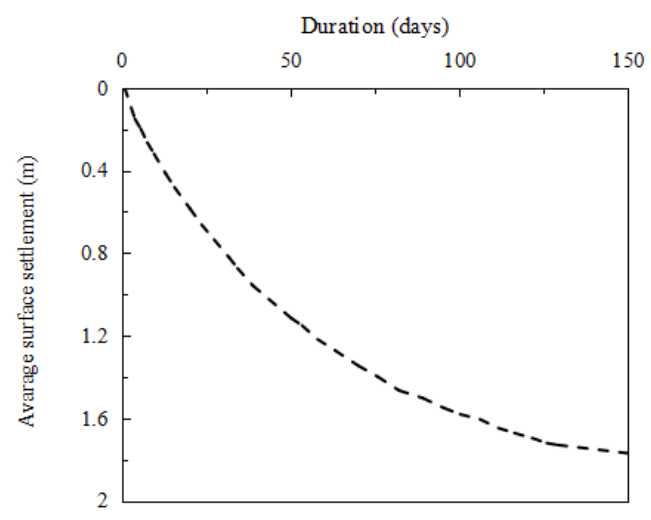

Figure 1. The changing of mean value of settlement on the surface in experiment yard

Fig. 1 reveals that the degree of the consolidation in the experiment yard goes up to over $85 \%$ after 150 days' preloading, and the velocity of the settlement on the surface is no larger than $2.5 \mathrm{~mm} /$ day. The final value of the settlement on the surface of the experiment yard after treatment is $1.777 \mathrm{~m}$.

\subsection{Exceed Pore pressure}

The exceed pore pressure in the middle area of experiment yard was tested through the construction period. There are 6 monitors for recording exceed pore pressure in different depths in the experiment yard, and they were set with $3 \mathrm{~m}$ intervals vertically. The vanishment of exceed pore pressure in this period and the gain in soil strength at different depths are traced. The changing in exceed pore pressure is shown in Fig.2.

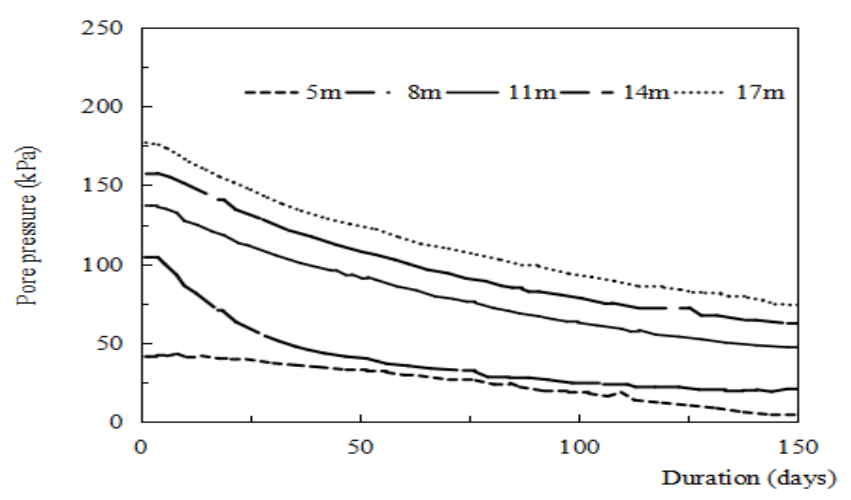

Figure 2. The changing in exceed pore pressure at different depths 
The exceed pore pressure at different depths reduced with the continues of the application of vacuum load. Exceed pore pressure of the shallow soil layers reduced rapidly, and deep soil had a smaller reduction velocity in exceed pore pressure.

\subsection{Settlement of soil layers}

The settlements of each layers were also checked in this experiment. There were 5 settlement monitors set with 3 $\mathrm{m}$ intervals veritically. The changing in layered settlements is shown in Fig.3.

\section{Duration (days)}

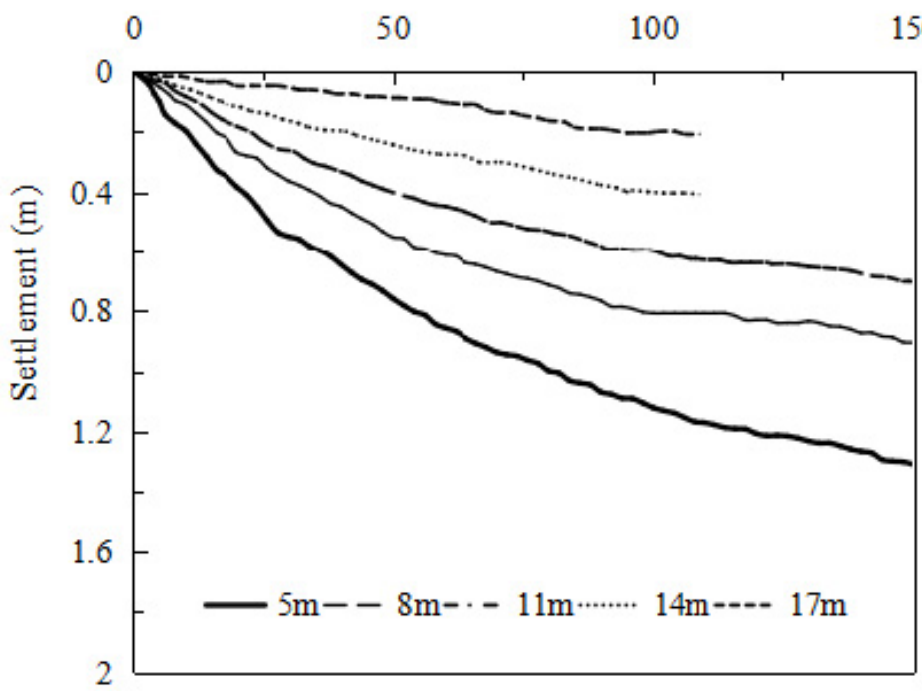

Figure 3. The changing in layered settlement

Layers at different depths deformed vertically with different settlement velocities. The settlement velocity is large in shallow layer and reduces rapidly with the increment in depth.

\section{Conclusions}

Our paper studiedthe application efficiency of traditional vacuum preloading method with the help of the data from an practical project, settlement and exceed pore pressure were tested to show the efficiency on the strength enforcement. The main conclusions are as followed.

- The degree of consolidation in the experiment yard goes up to $85 \%$ after 150 days application of the vacuum load, and the velocity of surface settlement remains no more than $2.5 \mathrm{~mm} /$ day. The total settlement after the treatment is 1.777 m.

- The exceed pore pressure changed with different velocities in different depths. Exceed pore pressure in shallow soil layers reduced more rapidly than deep layers.

- The settlement velocities of soil layers in different depths are different. The top weak dredger filled mud layer settles much faster than other layers.

\section{References}

1. Terzaghi, K. Theoretical Soil Mechanics, Wiley, New York, 1943.
2. Rendulic, L. Porenziffer and Porenwasserdruck in Tonen[J] Bauingenieur, 1936, 17, 559-564.

3. Barron, RA. Consolidation of fine grained soils by drain wells[J] Trans. ASCE, 1948, (113), 718-742.

4. Biot, MA. General theory of three-dimensional consolidation[J] Appl. Phys., 12, 155-164, 1941

5. Jelnlina, MK. Consolidation of clay by Means of Atmosphere Pressure [C] // Proceedings of a conference on soil stabilization, Boston: MITPress, 1952:258 